\title{
A brief history of the specialties from Federation to the present
}

\section{Catherine E Storey}

OAM, MBBS, MSC, FRACP

Clinical Associate Professor

School of Medicine, University of Sydney, Sydney, NSW.

catherine.storey@ sydney.edu.au

doi: 10.5694/mjal4.00136 n Australia, medical colleges have formed the framework on which specialisation has developed, and there are now 16 specialist medical colleges that represent all current major medical specialty groups (Box; and Appendix, online at mja.com.au). In 2011, there were about 24000 specialists and 12500 specialists-in-training. ${ }^{1}$ While specialisation is now an established part of the medical landscape, this was not the case at the time of Federation.

\section{The rise of "specialism" in Europe in the 19th century}

In the 18th century, unqualified itinerants performed restricted medical tasks, such as "cutting for stone" (surgical incision to remove urinary bladder calculi), "couching" cataracts (dislodging the cloudy lens using pressure or a surgical instrument and pushing it into the posterior chamber of the eye) and setting bones. Regular practitioners viewed these "specialists" as quacks or charlatans, and this perception was slow to dispel. ${ }^{2}$

Some historians argue that medical specialisation emerged in Paris in the wake of the French Revolution. ${ }^{3}$ Hospital-based medicine encouraged clinicopathological correlations, which focused attention on organ-specific abnormalities and the organ-specific specialist. ${ }^{4}$ Weisz, however, reasons that this and the "common-sense" explanation - that too much knowledge drove specialisation - do not completely explain its rise. He claims that the division of the population into smaller, manageable groups allowed a greater administrative rationalisation. ${ }^{5}$ Doctors gained more experience in a limited field, and this expertise led to better health outcomes. By 1860, there were more than 66 specialty hospitals in London alone. ${ }^{2}$ The rise of the hospital system promoted the elite consultant, and specialisation flourished.

\section{Specialisation in Australia at the time of Federation}

After Federation in 1901, Australia was for a time a union of disparate states. There were no local opportunities for postgraduate study, ${ }^{6}$ and difficulties with transportation and communication retarded most opportunities for interprofessional support locally and internationally. ${ }^{7}$ Despite these difficulties, the inaugural Intercolonial (later Australasian) Medical Congress convened in 1887 and offered the first opportunities for true professional interaction in specialty fields. ${ }^{8}$ Some practitioners, however, saw this development as pernicious - an easy way for the unscrupulous practitioner to achieve both financial gain and social prestige at the expense of the general practitioner. ${ }^{9}$

In 1901, all teaching hospitals had departments of ophthalmology, otorhinolaryngology and gynaecology, although there was little evidence of any organised specialisation. ${ }^{6}$ Consultants who established hospital clinics were rarely able to support these specialties in private practice. ${ }^{6}$

\section{The foundation of the colleges (1920-1950)}

The First World War (WWI) significantly transformed the medical workforce through the "first concentrated invasion of medical practice by the specialties". ${ }^{6}$ Many surgeons emerged from the war with practical experience in the fields of neuro-, thoracic and reconstructive surgery, as well as orthopaedics and anaesthetics. In Australia, the British Medical Association (BMA) created permanent postgraduate committees at state level, with representatives from universities and teaching hospitals providing postgraduate education programs as part of retraining returned service personnel. ${ }^{10}$

By 1920, some practitioners raised concerns about the trend towards specialisation. There was general agreement that both training and accreditation were haphazard and required both clarity and uniformity. ${ }^{11}$ One editorial in the Medical Journal of Australia expressed the "need for extended study, additional hospital experience and the selective influence of a stiff test", 12 all of which would eventuate in the fullness of time.

As early as 1920, Sir Louis Barnett, a New Zealand surgeon, proposed the formation of an Australasian surgical association. Surgeons initially rejected this proposal,

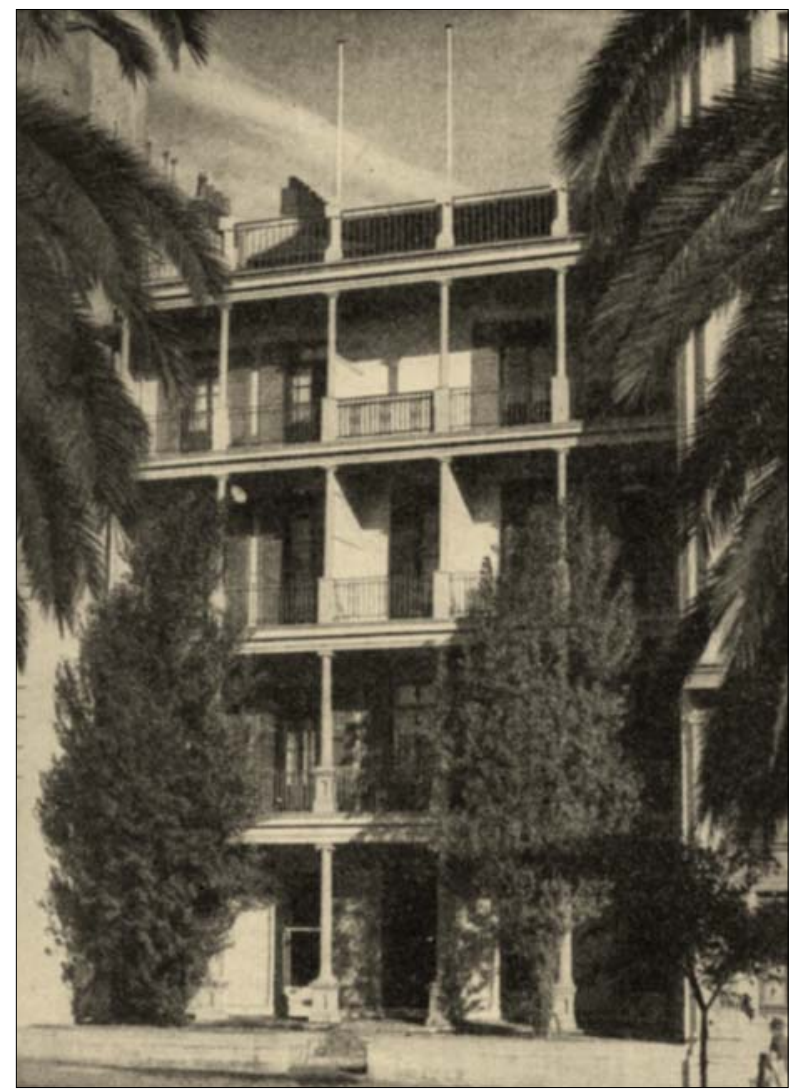

Building in Macquarie Street, Sydney, purchased in 1937 to be the Royal Australasian College of Physicians' headquarters (photograph, Med J Aust 1951; 1: 3). 
suggesting that the universities were the traditional educational bodies and that the BMA, with branches in all states, was the appropriate regulator of professional practice. ${ }^{13}$ The universities did provide postgraduate qualification in surgery, but these degrees examined only theoretical knowledge, lacked uniformity and in time proved inadequate to ensure surgical technical competency. ${ }^{14}$

In 1924, a delegation from the American College of Surgeons arrived in Australia offering membership to local surgeons of proven ability. This provided the catalyst for the establishment of a similar exclusive organisation for Australian and New Zealand surgeons. The (later Royal) Australasian College of Surgeons (RACS) formed in 1927 "to promote the art and science of surgery". The college aimed to achieve these goals by taking responsibility for specialist postgraduate surgical training, establishing standards of surgical competence by examination and ensuring the ethical standards of its members. ${ }^{15}$ Membership was initially restricted to those who already held a higher surgical qualification. In practice, many saw this as a way to restrict the scope of operations performed by general practitioners. ${ }^{15}$

Internal medicine also flourished in the wake of WWI, as a consequence of a "biophysical and biochemical turn". ${ }^{16}$ The clinical entity of coronary artery occlusion was described in 1912, and its diagnosis by electrocardiography was described in 1920; insulin was discovered in 1921.16 This was a time of rapid expansion of diagnostic capabilities and therapeutic interventions, which required a more complex clinical approach.

In 1930, a group of "representative physicians of Sydney and Melbourne" formed the Association of Physicians of Australasia, from which the Royal Australasian College of Physicians evolved. Incorporation was complete in 1938, and the first examinations for membership were held in the same year. The college expected every physician to practise as a generalist, and for the next 35 years it discouraged any further subspecialisation. ${ }^{17}$

A period of overseas training with membership of a British college remained, however, a sine qua non for the aspiring specialist well after the incorporation of these colleges until, in the 1970s, the colleges took over the responsibility for accrediting all postgraduate training positions. ${ }^{17}$

\section{The dominance of the teaching hospital and the rise of the subspecialties (1950-1975)}

By 1951, the colleges had made a significant impact on postgraduate education and the universities had largely relinquished their role in postgraduate specialised training and qualification. ${ }^{6}$ Within the teaching hospitals, consultants (initially all generalists) continued to provide their services free of charge on an "honorary" basis. A strict means-tested regime determined which patients could attend the outpatient department or be admitted as inpatients to these public hospitals; however, consultants viewed an appointment to a teaching hospital as the ultimate accolade. This established a hierarchy among their ranks, and the prestige associated with such a position ensured a profitable private referral practice. In private practice, specialists were free to determine individual fees according to their self-assessed expertise, seniority and reputation. ${ }^{18}$

\begin{tabular}{|c|c|}
\hline Royal Australasian College of Surgeons (RACS) & 1927 \\
\hline Royal Australasian College of Physicians (RACP) & 1938 \\
\hline Royal Australian and New Zealand College of Radiologists (RANZCR) & 1949 \\
\hline Royal College of Pathologists of Australasia (RCPA) & 1956 \\
\hline Royal Australian College of General Practitioners (RACGP) & 1958 \\
\hline Royal Australian and New Zealand College of Psychiatrists (RANZCP) & 1963 \\
\hline Royal Australasian College of Dental Surgeons (RACDS) & 1965 \\
\hline Australasian College of Dermatologists (ACD) & 1966 \\
\hline Royal Australasian College of Medical Administrators (RACMA) & 1967 \\
\hline Royal Australian and New Zealand College of Ophthalmologists (RANZCO) & 1969 \\
\hline Australasian College for Emergency Medicine (ACEM) & 1984 \\
\hline Australian and New Zealand College of Anaesthetists (ANZCA) & 1992 \\
\hline Australian College of Rural and Remote Medicine (ACRRM) & 1997 \\
\hline $\begin{array}{l}\text { Royal Australian and New Zealand College of Obstetricians and } \\
\text { Gynaecologists (RANZCOG) }\end{array}$ & 1998 \\
\hline Australasian College of Sports Physicians (ACSP) & 1999 \\
\hline College of Intensive Care Medicine of Australia and New Zeal & 2008 \\
\hline
\end{tabular}

During the 1950s, subspecialties began to emerge as discrete clinical units in teaching hospitals. ${ }^{19}$ Intensive care units proliferated to manage the acutely ill; coronary care units enhanced coordinated care of patients diagnosed with myocardial infarctions. The general surgeon began to relinquish many of his (very rarely her) traditional operations to the emerging specialty surgeons, further fragmenting the medical workforce. ${ }^{20}$ By the 1970 s, hospital-based salaried specialists took over many of the responsibilities for the management of these high-technology disciplines.

In 1950, thoracic surgery was the first subspecialty to be officially recognised by the RACS; and, progressively, divisions, sections and faculties eroded the concept of a generalist in all of the colleges. ${ }^{19,20}$ was general agreement that both training and accreditation and required both clarity and uniformity

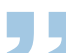
were haphazard

\section{Enter the federal government (1975)}

In 1975, the then Labor government introduced Medibank (reincarnated as Medicare in 1984), which guaranteed universal health cover for all Australians. Patients no longer had to bear the often prohibitive cost of seeing specialists in their private rooms. All patients now had affordable access to specialists, public hospitals and high-tech diagnostics. A schedule of medical fees, which set fees paid to specialists at a higher rate than general practitioners, determined the reimbursement paid to doctors. ${ }^{18,21}$ The newly formed National Specialist Qualification Advisory Committee (NSQAC) oversaw the recognition of specialists' qualifications for the purpose of payment of this higher fee, and for the first time since Federation, an official agency defined specialist practitioners in all states and territories. Hospital consultants now received sessional payments for their attendance and became "visiting" medical officers, leading to the demise of the honorary system. ${ }^{22}$ The Australian Medical Council (AMC) subsequently took over the role of the NSQAC and expanded its scope. Since 2001, the AMC has been responsible for the accreditation of all specialist vocational training and professional development programs, previously the exclusive domain of the colleges. ${ }^{23}$ 
The AMC now accredits, after a substantial review, all requests to establish new specialties and colleges. ${ }^{23}$

In recent years, there has been an unprecedented expansion of subspecialties, with many specialists forsaking the public hospital system for private hospitals or exclusive private practice. The teaching hospital is no longer the "Holy Grail" of the aspiring specialist.

What of the current status of specialisation? A 2013 review of the Australian health workforce highlighted the unrestrained growth of specialist services. ${ }^{24}$ This increase, partly driven by the increasing earning differential, has been at the expense of the generalist. Some specialties are more popular as a career path among doctors than others. Most specialist practices cluster in urban regions, giving rise to issues of equity of access, particularly for people from rural and regional centres.

In 1951, Sir Charles Bickerton Blackburn warned of "an increasing tendency for specialties to become isolated medical cults rather than parts of a coordinated system". ${ }^{6}$ This may apply equally to contemporary specialty practice: the current specialist workforce does not necessarily reflect community needs, and the rebalance will be a challenge for the future.

Competing interests: No relevant disclosures.

Provenance: Commissioned; externally peer reviewed.

1 Australian Institute of Health and Welfare. Medical workforce 2011. Canberra: AlHW, 2013. (AlHW Cat. No. HWL 49.) http://www.aihw.gov.au/ publication-detail/?id=60129542627 (accessed May 2014).

2 Porter R. The greatest benefit to mankind. A medical history of humanity from antiquity to the present. London: Fontana Press, 1997.

3 Ackerknecht EH. Medicine at the Paris Hospital, 1794-1848. Baltimore: Johns Hopkins Press, 1967.

4 Weisz $G$. The emergence of medical specialization in the nineteenth century. Bull Hist Med 2003; 77: 536-575.

5 Weisz G. Divide and conquer: a comparative history of medical specialization. New York: Oxford University Press, 2006.

6 Blackburn CB. The growth of specialism in Australia during fifty years and its significance for the future. Med J Aust 1951; 1: 20-24.
7 Gandevia B. The medico-historical signficance of young and developing countries, illustrated by Australian experience. In: Clarke E, editor. Modern methods in the history of medicine. London: The Athlone Press, 1971: 75-98.

8 Transactions of the Intercolonial Medical Congress of Australasia: first session held in Adelaide, South Australia, August-September 1887. Adelaide: Vardon and Pritchard, 1888.

9 Turner D. Evils of specialism. Intercolonial Medical Congress of Australasia transactions of second session, held in Melbourne, Victoria, January 1889. Melbourne: Stillwell and Co., 1889: 551-554.

10 McIntosh AM. The development of post-graduate training in medicine in Australia. Med J Aust 1951; 1: 28-32.

11 Australasian Medical Congress. Transactions of the eleventh session held in Brisbane, Queensland. Brisbane: Anthony James Cumming, Government Printer, 1921.

12 Armit HW. Specialists and specialties. Med J Aust 1920; ii: 437-438.

13 Beasley AW. The mantle of surgery. The first seventy-five years of the Royal Australasian College of Surgeons. Melbourne: RACS, 2002. http:// www.surgeons.org/about/college-history/history/the-mantle-of-surgery (accessed May 2014).

14 Wilde SDH. Practising surgery: a history of surgical training in Australia, 1927-1974 [PhD thesis]. Melbourne: Centre for the Study of Health and Society, University of Melbourne, 2003. http://repository.unimelb.edu. au/10187/8838 (accessed Jun 2014).

15 Syme GA. The aims and objects of the College of Surgeons of Australasia. Med J Aust 1928; 1: 488-491.

16 McDonald CG. Internal medicine: its development and practice in Australia during fifty years. Med J Aust 1951; 1: 1-5.

17 Winton R. Why the pomegranate? A history of the Royal Australasian College of Physicians. Sydney: RACP, 1988.

18 Repin GD. They can't say they weren't warned! Med J Aust 2000; 173: 17-19.

19 Wiseman JC, editor. To follow knowledge. A history of examinations, continuing education and specialist affiliations of the Royal Australasian College of Physicians. Sydney: RACP, 1988.

20 Lord RS. The fragmentation of general surgery. Aust N Z J Surg 1992; 62: 175-180.

21 Van der Weyden MB. Medibank, 25 years on: looking back, looking forward. Med J Aust 2000; 173: 2

22 Meeting of Presidents/Chairmen of State and Territory Medical Boards and representatives of Specialist Recognition Committees; 1972 Jun 15; Adelaide [minutes of inaugural meeting, accessed from the archives of the Royal Australasian College of Physicians].

23 Geffen L, editor. Assuring medical standards: the Australian Medical Council 1985-2010. Canberra: AMC, 2010.

24 Health Workforce Australia. Health workforce 2025. Medical specialties. Volume 3. Adelaide: HWA, 2012. 